\title{
Understanding HIV and associated risk factors among religious groups in Zimbabwe
}

Munyaradzi Mapingure ${ }^{1}$, Zindoga Mukandavire ${ }^{2,3}$, Innocent Chingombe ${ }^{1}$, Diego Cuadros ${ }^{4}$, Farirai Mutenherwa ${ }^{5}$, Owen Mugurungi $i^{6}$ and Godfrey Musuka ${ }^{1 *}$

\begin{abstract}
Background: The influence of religion and belief systems is widely recognized as an important factor in understanding of health risk perception and myths in the general fight against the HIV pandemic. This study compares the understanding of HIV risk factors and utilization of some HIV services among religious groups in Zimbabwe.
\end{abstract}

Methods: We conducted secondary data statistical analysis to investigate the understanding of HIV and associated risk factors among religious groups in Zimbabwe using 2015-2016 Zimbabwe Demographic and Health Survey (ZDHS) data. We began by investigating associations between understanding of HIV and associated risk factors among religious groups. A multivariate stepwise backward elimination method was carried out to explore factors determining understanding of HIV risk after controlling for confounding factors using the most recent ZDHS data (2015-2016).

Results: The results from the three surveys showed that, in general apostolic sector had low understanding of HIV and associated risk factors compared to other religious groups. Analysis of the 2015-2016 ZDHS data showed that women belonging to the apostolic sector were less likely to know where to get an HIV test odds ratio (OR) and 95\% confidence interval, 0.665 (0.503-0.880) and to know that male circumcision reduces HIV transmission OR 0.863 (0.781-0.955). Women from this group had no knowledge that circumcised men can be infected if they do not use condoms OR 0.633 (0.579-0.693), nor that it is possible for a healthy-looking person to have HIV, OR 0.814 (0.7190.921). They would not buy vegetables from a vendor with HIV OR $0.817(0.729-0.915)$ and were less likely to support that HIV positive children should be allowed to attend school with HIV negative children OR 0.804 (0.6800.950). Similar results were obtained for men in the apostolic sector. These men also did not agree that women were justified to use condoms if the husband has an Sexually Transmitted Infection (STI) OR 0.851 (0.748-0.967).

Conclusions: Our results suggest that apostolic sector lack adequate knowledge of HIV and associated risk factors than other religious groups. Targeting HIV prevention programmes by religious groups could be an efficient approach for controlling HIV in Zimbabwe.

Keywords: HIV, Risk factors, Religious groups, Prevention

\footnotetext{
*Correspondence: gm2660@cumc.columbia.edu

${ }^{1}$ ICAP at Columbia University, Harare, Zimbabwe

Full list of author information is available at the end of the article
}

(c) The Author(s). 2021 Open Access This article is licensed under a Creative Commons Attribution 4.0 International License, which permits use, sharing, adaptation, distribution and reproduction in any medium or format, as long as you give appropriate credit to the original author(s) and the source, provide a link to the Creative Commons licence, and indicate if changes were made. The images or other third party material in this article are included in the article's Creative Commons licence, unless indicated otherwise in a credit line to the material. If material is not included in the article's Creative Commons licence and your intended use is not permitted by statutory regulation or exceeds the permitted use, you will need to obtain permission directly from the copyright holder. To view a copy of this licence, visit http://creativecommons.org/licenses/by/4.0/ The Creative Commons Public Domain Dedication waiver (http://creativecommons.org/publicdomain/zero/1.0/) applies to the data made available in this article, unless otherwise stated in a credit line to the data. 


\section{Introduction}

Religion has a permeating influence on all aspects of life $[1,2]$. Its role in explaining health access and health outcomes has received considerable scholarly debate in Africa [3-5]. The church, as a community, provides a unique platform for informal social interaction as well as formal teaching and regulation, thus shaping individual attitudes towards healthseeking behavior [6]. The influence of religious organizations is widely recognized as an important factor in the fight against the HIV epidemic, particularly in sub-Saharan Africa [7-9]. However, the causal mechanisms that explain the associations between religion and health have largely been inconclusive [10]. On the one hand, there are arguments that support the view that church doctrine; religious beliefs and values have a direct influence on health outcomes [10], while on the other hand, others maintain that the observed differences on health outcomes are not a result of religion itself but rather due to

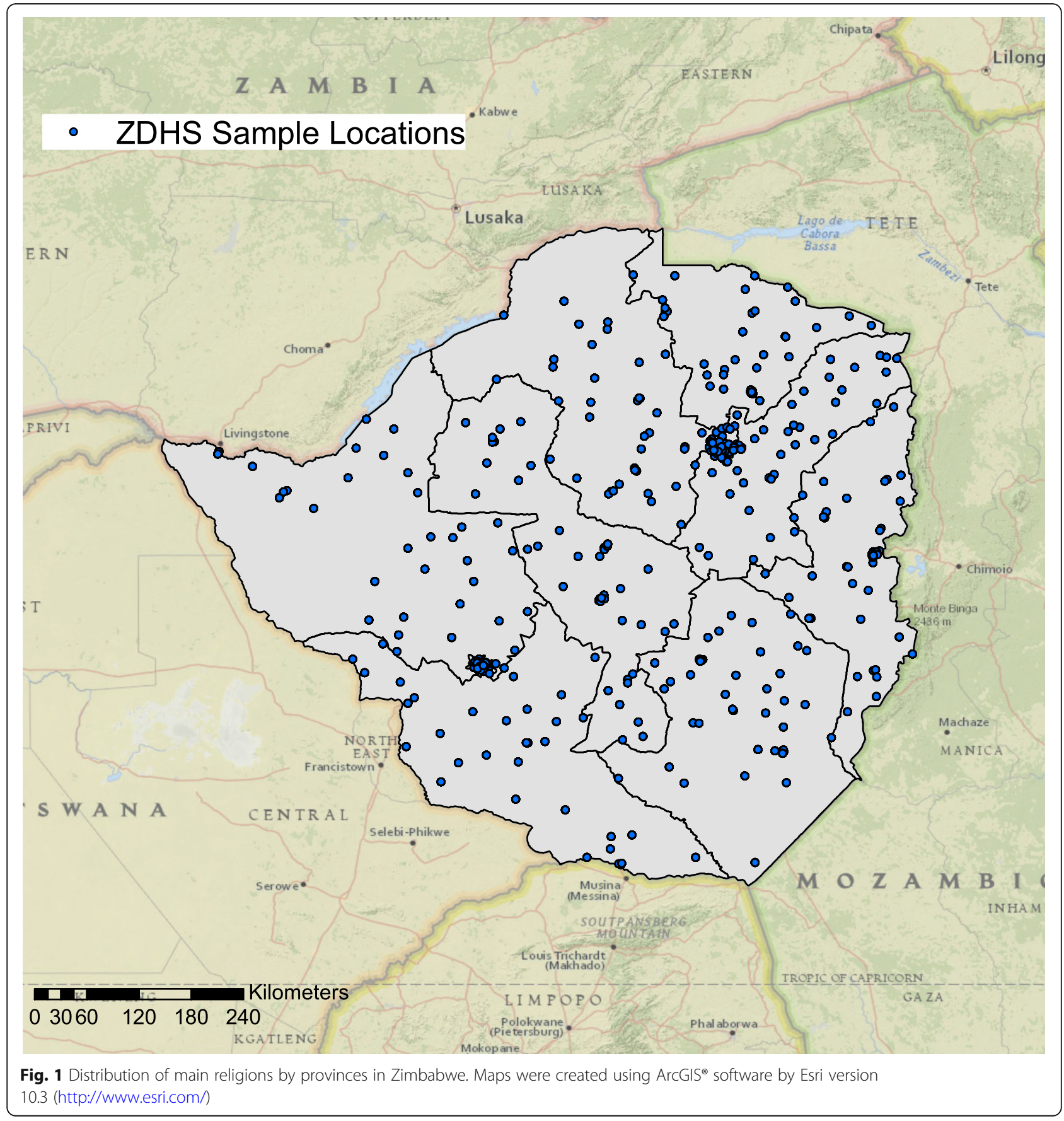


differential access to social and human capital [11, 12]. The effects of religious affiliation on health and their implications for prevention and care programmes therefore require further studying in order to guide the design of effective HIV prevention and mitigation programmes.

Zimbabwe is predominantly a Christian nation. Approximately, $87 \%$ of the population practice Christianity [13] under different church denominations [14]. According to the 2015 Zimbabwe Demographic and Health Survey (ZDHS), Apostolics were identified as the largest religious denomination in the country constituting $38 \%$ of the population ages $15-49$ years [13], and is the most common religion denomination in most of the provinces in Zimbabwe (Fig. 1). Other religious affiliations in the country were distributed as follows: Pentecostal 22\%, Protestant 16\%, Roman Catholic 7\%, Other Christian 5\%, no religion $11 \%$, traditional $2 \%$ and Moslem $1 \%$ [13]. In spite of the popularity of Christianity in the country there is great variability amongst the different churches and denominations in terms of beliefs, teachings and practices on sexual and health seeking behaviors. For example, while polygamy is not approved in the mainline churches, in particular those with Missionary foundations, it is acceptable in most African "Independent, Initiated, Indigenous, Instituted" Churches (AICs) [15]. The provision and promotion of western health beliefs and medicine, while abhorrent to most AICs, is widely accepted by the mainline churches $[14,15]$.

Although the last decade has seen the rapid emergence and expansion of Charismatic Evangelical denominations, primarily dominated by the Pentecostal churches, the apostolic churches still have a substantial following [15]. Christians who practice the apostolic 'brand' of faith religion are commonly referred to as Vapositori, a Shona adaptation of the word "apostolics" $[4,5,16]$. A trend analysis suggests that there has been a steady increase on group membership among the apostolics from 20\% of the Zimbabwean population in the 1990s [17] to $27 \%$ in 2009 [18] and currently at 38\% [13]. Forty two percent of the women respondents reported that they belonged to the apostolic sect [13]. Of the several apostolic churches in Zimbabwe, the Johanne Marange and Johanne Masowe apostolic groups command a huge following with members spread across the African continent and beyond [19].

It must be highlighted, however, that the collective term vapositori masks the diversity among Christians commonly identified by this name. For example, they differ on theological foundations, are quite varied in terms of their beliefs, values, teachings, regulations and practices. An attempt to profile these churches is documented elsewhere [4] and is beyond the scope of this study. However, for comparative purposes, we adopt a taxonomy reported by Maguranyanga (2011), which categorizes apostolics on a continuum that ranges from the "ultra conservative" or "fundamentalists" to the "semiconservative" and "liberal" apostolic groups based on their beliefs on uptake of modern medical services. The ultra-conservative apostolics teach against any access and utilization of modern healthcare services and place great emphasis on faith healing through prayers, the use of holy water and stones while the semi-conservative groups neither object nor openly promote use of modern medicine and actively seek healthcare [4]. All these attributes and characteristics are mirrored in the followers' health seeking practices and attitudes towards conventional medicine.

Most of the available literature on the role of religion in Zimbabwe, in general and the apostolics in particular, on access to health services specifically has focused on small cross-sectional studies within specific geographic areas [20-22]. Consequently, these studies may not have been representative of the group nationally and the other southern African countries where this group exists. For example, a study conducted in Manicaland demonstrated the negative impact of affiliation to an apostolic church to child mortality [20]. Another study showed that mothers belonging to the Apostolic faith were less likely to have used postnatal care services in an urban suburb in Harare [21]. There are few studies that have used population based national data to understand the relationship between religion and access to health in general and among the apostolics in particular, however, they have their fair share of limitations. For example, an analysis of data from the Zimbabwe's Demographic and Health Survey 2005 [23] showed that apostolic women were at higher risk of HIV infection because they married early. The study however, only controlled for age and did not account for other potential confounding effects. Another, nationally representative study showed that affiliation with the Apostolic faith was a significant risk factor in reducing utilization of maternal and child health services despite reduced costs, accessibility and availability of these services [10]. However, since the primary focus of the study was maternal and child health, the relationship between HIV and its associated risks was not explored and the study did not control for other confounding factors. Given this background, using data from a large nationally representative survey (ZDHS) this study investigates the understanding of the HIV epidemic and associated risk factors for HIV infection among religious groups in Zimbabwe.

\section{Methods}

Study area and data sources

The ZDHS study area was Zimbabwe which has one of the highest burden of HIV in the world, with approximately 1.2 million persons aged $15-64$ years old 


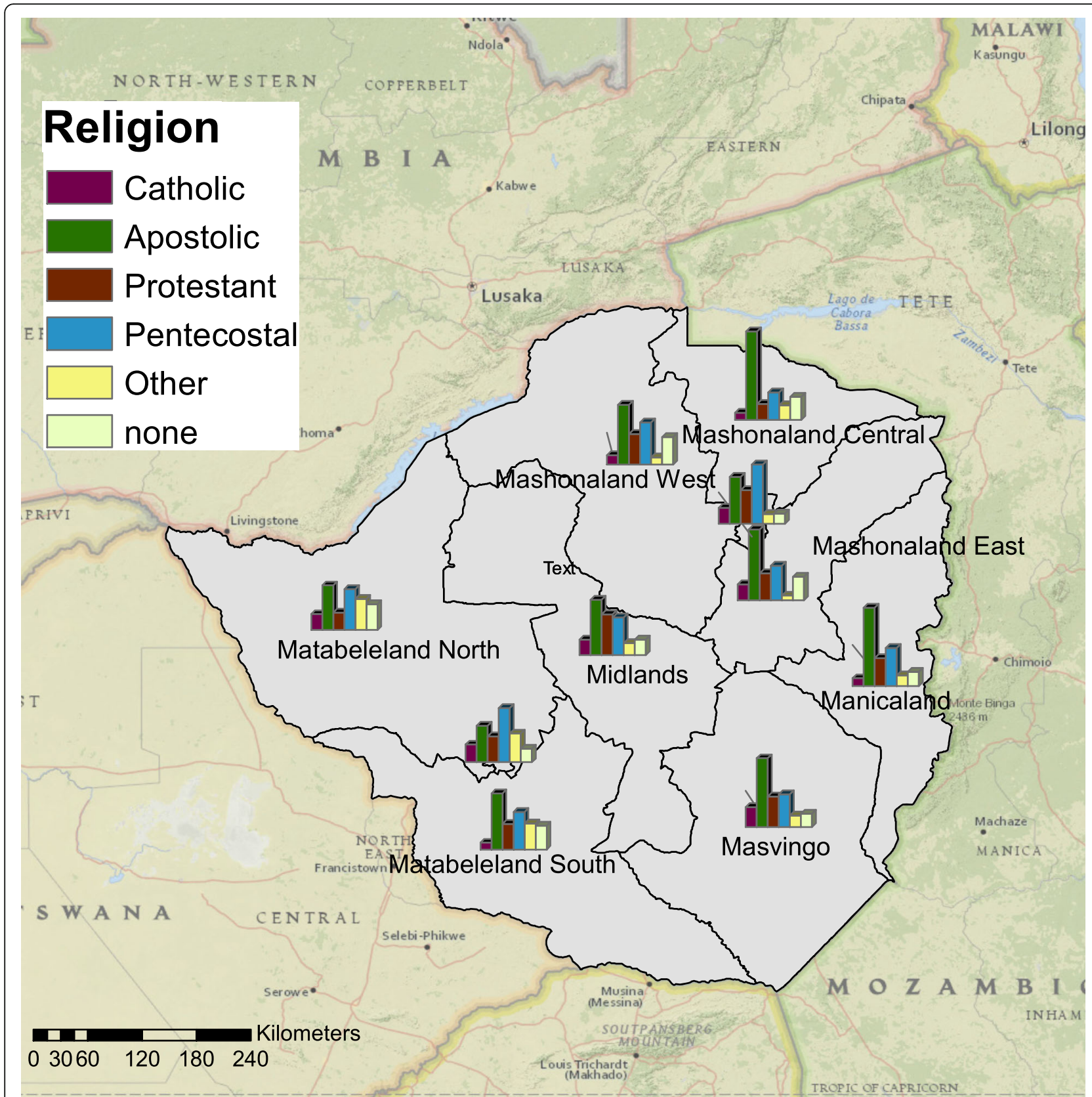

Fig. 2 Zimbabwe Demographic and Health Survey (ZDHS) sample locations (blue dots). Maps were created using ArcGIS ${ }^{\circledR}$ software by Esri version 10.3 (http://www.esri.com/)

living with HIV in 2016 [24]. The main source of secondary data for this study was the most recent ZDHS [25]. Figure 2 shows the geographic locations utilized for sample collection.

\section{Statistical analysis}

Firstly, we explored associations between variables using simple chi-square test for categorical variables. Thereafter, multivariate stepwise backward elimination method was used to explore factors significantly associated with the understanding of the HIV infection and associated risk factors comparing apostolic and other religions after controlling for confounding among these factors. Two models were analyzed separately i.e. one for males and the other for females, to explore independent associations for each gender. Briefly, stepwise regression is a method of fitting regression models in which the choice of predictive variables is carried out by an automatic procedure in STATA or other statistical packages. We specifically conducted the backward 
Table 1 Baseline frequencies for participant characteristics using ZDHS 2015-16 data

\begin{tabular}{|c|c|c|}
\hline Variable & Female Frequency n (\%) & Male frequency $\mathrm{n}(\%)$ \\
\hline \multicolumn{3}{|l|}{ Age group in years } \\
\hline $15-19$ & $2156(22)$ & $2065(25)$ \\
\hline $20-24$ & $1782(17)$ & $1376(16)$ \\
\hline $25-29$ & $1656(17)$ & $1166(14)$ \\
\hline $30-34$ & $1591(16)$ & $1104(13)$ \\
\hline $35-39$ & $1209(12)$ & $932(11)$ \\
\hline $40-44$ & $966(10)$ & $797(9)$ \\
\hline $45-49$ & $595(6)$ & $578(7)$ \\
\hline 50-54 (Men only) & & $378(5)$ \\
\hline \multicolumn{3}{|l|}{ Type of residence } \\
\hline Urban & $4521(38)$ & $3456(41)$ \\
\hline Rural & $5434(62)$ & $4940(59)$ \\
\hline \multicolumn{3}{|l|}{ Highest education level } \\
\hline None & $106(1)$ & $57(1)$ \\
\hline Primary & $2385(26)$ & $1855(22)$ \\
\hline Secondary & $6637(66)$ & $5524(66)$ \\
\hline Higher & $827(7)$ & $960(11)$ \\
\hline \multicolumn{3}{|l|}{ Marital status } \\
\hline Never in union & $2666(25)$ & $3619(43)$ \\
\hline Married & $5700(59)$ & $4267(51)$ \\
\hline Living with partner & $315(3)$ & $70(1)$ \\
\hline Widowed & $430(4)$ & $66(1)$ \\
\hline Divorced & $488(5)$ & $163(2)$ \\
\hline Separated & $356(4)$ & $211(3)$ \\
\hline \multicolumn{3}{|l|}{ Religion } \\
\hline Traditional & $60(1)$ & $220(3)$ \\
\hline Roman catholic & $670(7)$ & $698(8)$ \\
\hline Protestant & $1618(16)$ & $1272(15)$ \\
\hline Pentecostal & $2679(25)$ & $1551(18)$ \\
\hline Apostolic sect & $3829(42)$ & $2507(30)$ \\
\hline Other Christian & $589(5)$ & $606(7)$ \\
\hline Muslim & $30(0)$ & $53(1)$ \\
\hline None & $471(5)$ & 1479 (18) \\
\hline Other & $9(0)$ & $10(0)$ \\
\hline
\end{tabular}

elimination procedure which involves starting with all candidate variables, testing the deletion of each variable using a chosen model fit criterion, deleting the variable (if any) whose loss gives the most statistically insignificant deterioration of the model fit, and repeating this process until no further variables can be deleted without a statistically significant loss of fit. Additionally, we used the current ZDHS 2015-16 and two previous rounds done in 2010-11 and 2005-06 to conduct some chisquare tests on the HIV knowledge and HIV risk factor variables. We conducted additional analysis on the latest round of DHS as recent data would more useful in shaping the current HIV programming techniques in Zimbabwe,

\section{Results}

Demographic characteristics for 2015 ZDHS survey

The demographic characteristics for the ZDHS 2015 are presented in Table 1. More than half of the $(62 \%$ for females and $59 \%$ for males) survey participants of the population lived in rural areas. Two thirds, (66\% for both sexes) of survey participants had secondary education. 
Table 2 Factors associated with the apostolic sector analyzed separately for males and females from ZDHS 2015-16 data

\begin{tabular}{ll} 
Variable & Females $\mathrm{n}(\%)$ \\
\cline { 2 - 2 } & Apostolics
\end{tabular}

Other religion $\quad P$ value

\section{Males $\mathbf{n}(\%)$}

Ever heard about HIV

$\begin{array}{ll}\text { No } & 55(1.4) \\ \text { Yes } & 3774(98.6)\end{array}$

Ever tested for HIV

$\begin{array}{lll}\text { No } & 805(21.9) & 1085(17.5) \\ \text { Yes } & 3024(78.1) & 5041(82.5)\end{array}$

Know where to get tested

$\begin{array}{lll}\text { No } & 126(3.6) & 124(2.3) \\ \text { Yes } & 496(96.4) & 5947(97.7)\end{array}$

HIV transmission can be reduced by having 1 sexual partner

$\begin{array}{lll}\text { No } & 7282(7.6) & 330(5.4) \\ \text { Yes } & 3434(90.8) & 5705(93.5) \\ \text { Don't know } & 58(1.6) & 57(1.1)\end{array}$

Condom use reduces HIV

$\begin{array}{lll}\text { No } & 519(13.9) & 705(11.8) \\ \text { Yes } & 3125(82.1) & 5282(86.0) \\ \text { Don't know } & 130(4.0) & 105(2.2)\end{array}$

Men can reduce HIV transmission by being circumcised

$\begin{array}{lll}\text { No } & 672(18.2) & 829(13.7) \\ \text { Yes } & 2733(71.1) & 4794(77.6) \\ \text { Don't know } & 369(10.7) & 469(8.6)\end{array}$

Circumcised men who have sex without condom can get HIV/AIDS

$\begin{array}{lll}\text { No } & 981(26.5) & 1029(17.4) \\ \text { Yes } & 2210(56.1) & 4357(68.7) \\ \text { Don't know } & 583(17.4) & 706(12.9)\end{array}$

Can get HIV from sharing food

$\begin{array}{lll}\text { No } & 3371(89.1) & 5672(93.2) \\ \text { Yes } & 312(8.2) & 343(5.3) \\ \text { Don't know } & 91(2.7) & 77(1.5)\end{array}$

Can get HIV by witchcraft or supernatural means

$\begin{array}{lll}\text { No } & 3456(91.8) & 5696(93.8) \\ \text { Yes } & 239(6.0) & 306(4.6) \\ \text { Don't know } & 79(2.2) & 90(1.6)\end{array}$

A healthy person can be HIV infected

$\begin{array}{lll}\text { No } & 604(15.7) & 680(11.3) \\ \text { Yes } & 3131(83.1) & 365(87.8) \\ \text { Don't know } & 39(1.2) & 47(0.9)\end{array}$

Would be ashamed if a family member gets infected with HIV

$\begin{array}{lll}\text { Disagree } & 3253(85.4) & 5469(89.0) \\ \text { Agree } & 511(14.4) & 607(10.7) \\ \text { Don't know } & 10(0.2) & 16(0.3)\end{array}$

Would buy vegetables from a vendor with HIV

$\begin{array}{lll}\text { No } & 61(23.4) & 968(16.4) \\ \text { Yes } & 2888(76.0) & 5093(82.9) \\ \text { Don't know } & 25(0.6) & 31(0.7)\end{array}$

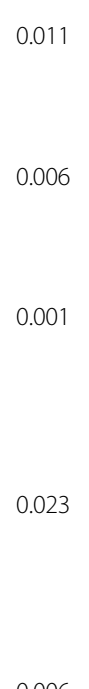

0.001

0.001

$$
523 \text { (22.2) }
$$$$
1946(81.5)
$$$$
11(0.4)
$$$$
464 \text { (18.3) }
$$$$
2002 \text { (81.2) }
$$$$
0.001
$$

$14(0.5)$
Apostolics

Other religion

$P$ value

$28(0.5)$

5861 (99.5)

0.002

$1873(32.2)$

4016 (67.8)

0.001

$\begin{array}{ll}300(11.8) & 517(9.1) \\ 2146(86.6) & 5298(90.1) \\ 34(1.6) & 46(0.8)\end{array}$

$170(3.0)$

$5691(97.0)$

0.001

251 (4.7)

5576 (94.7)

$34(0.7)$

0.062

$\begin{array}{ll}446(18.3) & 925(15.5) \\ 1907(76.5) & 4694(79.7) \\ 127(5.3) & 242(4.8)\end{array}$

0.001

$\begin{array}{ll}329(13.2) & 626(10.5) \\ 2016(81.2) & 5011(85.1) \\ 135(5.6) & 224(4.4)\end{array}$

0.016

$\begin{array}{ll}2197(88.8) & 5268(90.0) \\ 220(8.6) & 490(8.1) \\ 63(2.6) & 103(1.9)\end{array}$

0.134

$\begin{array}{ll}2279(92.2) & 5403(92.5) \\ 146(5.5) & 353(5.6) \\ 55(2.4) & 105(1.9)\end{array}$

0.001

$\begin{array}{ll}311(13.1) & 580(10.3) \\ 2150(85.9) & 5242(88.9) \\ 19(1.0) & 39(0.8)\end{array}$

0.442

0.005

4942 (77.4)

895 (16.0)

$24(0.56)$

0.001

$923(15.3)$

4879 (83.7)

$59(1.0)$ 
Table 2 Factors associated with the apostolic sector analyzed separately for males and females from ZDHS 2015-16 data (Continued)

\begin{tabular}{|c|c|c|c|c|c|c|}
\hline \multirow[t]{2}{*}{ Variable } & \multicolumn{3}{|c|}{ Females $\mathbf{n}(\%)$} & \multicolumn{3}{|l|}{ Males n (\%) } \\
\hline & Apostolics & Other religion & $P$ value & Apostolics & Other religion & $P$ value \\
\hline \multicolumn{7}{|c|}{ Children with HIV should be allowed to attend school with children without } \\
\hline No & $324(8.7)$ & $312(4.6)$ & & $245(9.2)$ & $486(8.1)$ & \\
\hline Yes & $3409(90.1)$ & $5741(94.6)$ & & $2211(89.9)$ & $5341(91.2)$ & \\
\hline Don't know & $41(1.2)$ & $39(0.8)$ & 0.001 & $24(0.9)$ & $34(0.7)$ & 0.201 \\
\hline \multicolumn{7}{|c|}{ Wife justified to ask husband to use a condom if he has an STI } \\
\hline No & $509(12.9)$ & $662(10.2)$ & & $397(16.0)$ & $670(12.3)$ & \\
\hline Yes & $3240(84.8)$ & $5372(88.2)$ & & $2076(82.6)$ & $5164(86.7)$ & \\
\hline Don't know & $80(2.3)$ & $92(1.6)$ & 0.040 & $34(1.4)$ & $55(1.0)$ & 0.001 \\
\hline \multicolumn{7}{|c|}{ Responded circumcised } \\
\hline No & & & & $2196(88.7)$ & $4861(84.2)$ & \\
\hline Yes & & & & $306(11.2)$ & $1021(15.7)$ & \\
\hline Don't know & & & & $5(0.2)$ & $7(0.1)$ & 0.001 \\
\hline
\end{tabular}

The Apostolic Sect was the largest religious group, constituting $40 \%$ of women and $30 \%$ of all adult males.

\section{HIV knowledge factors associated with the apostolic sect} The results in Table 2 shows that the apostolic males and females were less likely to have ever heard about HIV when respectively compared to males and females of other religions $(p<0.05)$ and ever tested for HIV. When compared to males and females of other religions the apostolic sect showed lower percentage of knowledge. Comprehensive knowledge on HIV was only $47 \%$ among females Apostolics compared to 60\% among non Apostolics females. Similarly, comprehensive knowledge on HIV was only $51 \%$ among males Apostolics compared to $58 \%$ among non Apostolics males.

\section{Adjusted regression model results for females}

As shown in Table 3, in multivariate stepwise regressing models, compared to women of other religions, women belonging to the Apostolic sect continued to fair negatively in the following items. They are less likely to know where to get an HIV test adjusted odds ratio (aOR) (95\% confidence interval $[\mathrm{CI}])=0.665(0.503-0.880), p=$ 0.004 , they are less likely to know that men can reduce their chance of getting HIV by being circumcised, aOR $(95 \% \mathrm{CI})=0.863(0.781-0.955), \quad p=0.004$. Apostolic women were likely to show misconception that one can get HIV from sharing food OR $(95 \% \mathrm{CI})=1.203(1.012-$ 1.429), $p=0.036$. On a positive note apostolic females had higher rate of HIV testing aOR 1283 (95\% CI 1.134-1.451).

\section{Adjusted regression model results for males}

As shown in Table 4, in multivariate stepwise regressing models, compared to men of other religions, men belonging to the apostolic sect were less likely to have been tested for $\mathrm{HIV}$, aOR $(5 \% \mathrm{CI})=0.825(0.743-0.916)$, $p=0.001$, or know where to get an HIV test, aOR

Table 3 Multivariate stepwise backward elimination model results for females: final model using ZDHS 2015 data

\begin{tabular}{|c|c|c|c|}
\hline Variable & Adjusted Odds Ratio & $95 \% \mathrm{Cl}$ & $P$ Value \\
\hline Ever tested for HIV & 1.283 & $1.134-1.451$ & 0.001 \\
\hline Know where to get tested & 0.665 & $0.503-0.880$ & 0.004 \\
\hline HIV transmission can be reduced by having 1 sexual partner & 0.900 & $0.765-1.059$ & 0.205 \\
\hline Men can reduce HIV transmission by being circumcised & 0.863 & $0.781-0.955$ & 0.004 \\
\hline Circumcised men who have sex without condom can get HIV/AIDS & 0.633 & $0.579-0.693$ & 0.001 \\
\hline Can get HIV from sharing food & 1.203 & $1.012-1.429$ & 0.036 \\
\hline Can get HIV by witcheraft or supernatural means & 1.134 & $0.943-1.362$ & 0.181 \\
\hline A healthy person can be HIV infected & 0.814 & $0.719-0.921$ & 0.001 \\
\hline Would be ashamed if a family member gets infected with HIV & 1.110 & $0.970-1.270$ & 0.129 \\
\hline Would buy vegetables from a vendor with HIV & 0.817 & $0.729-0.915$ & 0.001 \\
\hline Children with HIV should be allowed to attend school with children without HIV & 0.804 & $0.680-0.950$ & 0.011 \\
\hline
\end{tabular}


Table 4 Multivariate stepwise backward elimination model results for males: final model using ZDHS 2015 data

\begin{tabular}{llll}
\hline Variable & Adjusted Odds Ratio & $\mathbf{9 5 \%}$ Cl & P Value \\
\hline Ever tested for HIV & 0.825 & $0.743-0.916$ & 0.001 \\
Know where to get tested & 0.637 & $0.502-0.809$ & $0.665-0.895$ \\
Circumcised men who have sex without condom can get HIV/AIDS & 0.771 & 0.001 \\
Would be ashamed if a family member gets infected with HIV & 0.709 & $0.616-0.816$ \\
Wife justified to ask husband to use a condom if he has an STI & 0.851 & $0.748-0.967$ & 0.001 \\
Responded circumcised & 0.773 & $0.675-0.885$ & 0.014 \\
\hline
\end{tabular}

$(5 \% \mathrm{CI})=0.637(0.502-0.809), p=0.001$. The men were less likely to know that circumcised men who have sex without a condom can get $\mathrm{HIV}$ aOR $(5 \% \mathrm{CI})=0.771$ (0.665-0.895), $p=0.001$. Apostolic men were less likely to be circumcised aOR $(5 \% \mathrm{CI})=0.773(0.675-0.885)$, $p=0.001$.

\section{Trend of risk perception}

From data analysis results of the three rounds of ZDHS surveys, Apostolics male and females performed poorly in most questionnaire items related to their understanding of HIV and associated risk factors, see supplementary Tables 1a, b, 2a, b, 3 and 4 .

With regard to data on previous rounds of ZDHS, we also performed chi-square tests for various factors comparing the apostolic sect and people of other religions using the ZDHS 2010-2011 data (supplementary Table 3) and ZDHS 2005-2006 data (supplementary Table 4).

\section{Discussion}

We conducted a comparative analysis of understanding HIV risk factors among religions groups in Zimbabwe. Our findings support previous findings that Apostolics are lagging behind in terms of their behavior and understanding of HIV issues. Our findings are consistent with previous studies in Zimbabwe which shown that affiliation to an apostolic church has some impact on health seeking behavior, access to health and health outcomes $[4,10,20,21]$. This association could be explained in one of several ways. First, the church provides social support mechanisms in times of need, which potentially results in improved mental and physical health for church members. Second, the strict church doctrine on sex and sexuality and moral codes of conduct have a strong influence on members sexual practices and on individual and collective HIV risk perceptions [20, 26]. Thirdly, health, disease and illness are perceived to have primarily a spiritual foundation and healing is believed to come from prophets through acts of the Holy Spirit [4]. Any reliance on traditional or western preventative and curative services is therefore viewed as a display of lack of faith [5] and may be condemned and despised by some apostolic groups [4]. It is no wonder that some apostolic sects openly object to the uptake of modern medical health services including immunization and the taking of medicines [4, 27].

Univariate analysis showed that while knowledge of existence of HIV is universal, the percentages of apostolics who has this knowledge is slightly lower. The proportions of ever receiving an HIV test or knowing where HIV testing is done are also low for both males and females. Because Apostolic forms an increasingly large proportion of the people in Zimbabwe [13, 17, 18], targeting these groups with HIV testing messages and access to HIV testing, will certainly increase the first 90 of The Joint United Nations Programme on HIV/AIDS (UNIAIDS's) 90-90-90 targets. The construct variable for comprehensive knowledge of HIV also shows lack of knowledge among apostolic groups.

The results showed misconception with regards to HIV prevention and modes of transmission among apostolic males and females when compared to other religions. This pose serious challenges with regards to HIV prevention hence the need for targeted information around HIV transmission and prevention. Of note, is their failing to mention that HIV transmission can be reduced by having one HIV negative sexual partner who is faithful. This is also embodied in their religious teaching around having to be fruitful and multiply and of note is that apostolic groupings engage in polygamous marriages. The apostolic males and females are less likely to think that a healthy person may be having HIV infection and may therefore indulge in unsafe sex which would increase their chances of being positive. It is also disturbing to note that both male and female apostolic are less likely to think that a wife is justified to ask her husband to use a condom if he has an STI.

Our analysis also showed that male apostolic struggle with stigma issues and also on how they would relate to an HIV infected person. As previously reported [5] religion affects people's daily lives by solving social problems, although it creates others. Efforts to reduce stigma and discrimination around the apostolic is warranted.

It is worth noting that in multivariate regression models there are crucial HIV related factors that remained poor among these groups. The main 
limitation of this this study is that we did not disaggregate data on the apostolic sector as other studies have shown that it is not one homogenous group as captured by the ZDHS survey data but at least three groups: the ultraconservative, the semi-conservative and the liberal Apostolic groups which place varying emphasis on faith healing and the strict adherence to church beliefs against the use of modern medicine. However, our results may be interpreted as generalizing the situation among this group.

\section{Conclusions}

The study results give a more comprehensive information on understanding of HIV and associated risk factors amongst the largest key religious groups in Zimbabwe. These results show that HIV knowledge and understanding is lower in the Apostolic sector compared to other religious groups and the odds of HIV high risk behavior is higher in this sector than other religious groups. This association remained even after adequately controlling for other mediating factors. This conclusion is supported by a number of other studies on health seeking behavior generally amongst the apostolic sect but not specifically referring to HIV prevention and care services [5]. Some studies [4, 5] suggest that "religious teaching and church regulations, of the Apostolic sect groups for example faith healing, negatively shape healthcare-seeking behavior". It is important to highlight that this study focused on the association between HIV knowledge and religious practices and believes. This association should not be treated as evidence that it is the beliefs and practices of the different religious groups that explain the systematic differences we found, and thus our results should be interpreted with caution.

In order to overcome theological rigidity on health related issues among the apostolic sector, the Ministry of Health and Child Care (MoHCC) and its implementing partners should work more closely with apostolic sector representative organizations to develop enhanced, targeted information, education and communication materials and promotional events to address misinformation, myths and lack of understanding on HIV prevention and care.

\section{Supplementary Information}

The online version contains supplementary material available at https://doi. org/10.1186/s12889-021-10405-8.

\section{Additional file 1.}

\section{Abbreviations}

AICs: African "Independent, Initiated, Indigenous, Instituted" Churches; aOR: Adjusted Odds Ratio; EA: Enumeration Area; HIV: Human Immunodeficiency Virus; IRB: Institutional Review Board; MoHCC: Ministry of Health and Child Care; OR: Odds Ratio; STI: Sexually Transmitted Infection;
UNIAIDS: The Joint United Nations Programme on HIV/AIDS;

ZDHS: Zimbabwe Demographic and Health Survey

\section{Acknowledgements}

Authors would like to thank all respondents for their willingness to participate in the ZDHS study and for ICF Macro for making the data available.

\section{Authors' contributions}

GM conceived the study. GM and MM carried out the statistical analysis. GM wrote the first draft of the paper. All authors (MM, ZM, IC, DC, FM, OM \& GM) contributed to the writing of the manuscript. All authors (MM, ZM, IC, DC,

FM, OM \& GM) read and approved the final manuscript.

\section{Funding}

N/A.

\section{Availability of data and materials}

The data that support the findings of this study are available from the Demographic and Health Surveys (http://www.measuredhs.com) but restrictions apply to the availability of these data, which were used under license for the current study, and so are not publicly available.

\section{Ethics approval and consent to participate}

Procedures and questionnaires for standard Demographic Health Surveys (DHS) have been reviewed and approved by the ICF International Institutional Review Board (IRB). Additionally, country-specific DHS survey protocols are reviewed by the ICF IRB and typically by an IRB in the host country. The ICF International IRB ensures that the survey complies with the U.S. Department of Health and Human Services regulations for the protection of human subjects, while the host country IRB ensures that the survey complies with laws and norms of the nation. In the original primary data collection for each DHS, informed consent was sought from all participants prior to serological testing for HIV (http://dhsprogram.com/What-We-Do/Protecting-thePrivacy-of-DHS-Survey-Respondents.cfm\#sthash. Ot3N7n5m.dpuf). We sought and were granted permission to use the core dataset for this analysis by MEASURE DHS.

\section{Consent for publication}

Not applicable.

\section{Competing interests}

Drs Godfrey Musuka and Zindoga Mukandavire are Editorial Board members of BMC Public Health. All other authors declare that they have no competing interests.

\section{Author details}

${ }^{1}$ ICAP at Columbia University, Harare, Zimbabwe. ${ }^{2}$ Centre for Data Science, Coventry University, Coventry, UK. ${ }^{3}$ School of Computing, Electronics and Mathematics, Coventry University, Coventry, UK. ${ }^{4}$ University of Cincinnati, Cincinnati, USA. ${ }^{5}$ Biomedical Research \& Training Institute, Harare, Zimbabwe. ${ }^{6}$ Ministry of Health and Child Care, Harare, Zimbabwe.

Received: 9 June 2020 Accepted: 7 February 2021

Published online: 17 February 2021

\section{References}

1. Agadjanian V. Gender, religious involvement, and HIV/AIDS prevention in Mozambique. Soc Sci Med. 2005;61(7):1529-39

2. Chitando E. Theology in the HIV \& AIDS era series, module 1 - Gender, religion, and HIV and AIDS prevention. In: Dube MW, editor. Theology in the HIV \& AIDS era series The HIV \& AIDS curriculum for TEE programmes and institutions in Africa Geneva. edn. Geneva: World Council of Churches; 2007.

3. Ensor T, Cooper S. Overcoming barriers to health service access: influencing the demand side. Health Policy Plan. 2004;19(2):69-79.

4. Maguranyanga B. Apostolic religion, health and utilization of maternal and child health Services in Zimbabwe. Harare: UNICEF; 2011.

5. Munyaradzi Kenneth D, Marvellous M, Stanzia M, Memory DM. Praying until death: apostolicism, delays and maternal mortality in Zimbabwe. PLoS One. 2016;11(8):e0160170 
6. Agadjanian V, Menjivar C. Talking about the 'epidemic of the millennium': religion, informal communication, and HIV/AIDS in sub-Saharan Africa. Soc Probl. 2008;55:301-21.

7. Dilger $H$, Burchardt $M$, van Dijk R. Introduction - the redemptive moment: HIV treatments and the production of new religious spaces. AJAR. 2010;9(4):373-83.

8. Klaits F. The widow in blue: blood and the morality of remembering in Botswana's time of AIDS. J Int Afr Inst. 2005;75(1):46-62.

9. Olivier J, Tsimpo C, Gemignani R, Shojo M, Coulombe H, Dimmock F, Wodon Q. Understanding the roles of faith-based health-care providers in Africa: review of the evidence with a focus on magnitude, reach, cost, and satisfaction. Lancet. 2015;386(10005):1765-75.

10. Ha W, Salama P, Gwavuya S, Kanjala C. Is religion the forgotten variable in maternal and child health? Evidence from Zimbabwe. Soc Sci Med. 2014; 118:80-8.

11. Gyimah SO, Takyi BK, Addai I. Challenges to the reproductive-health needs of African women: on religion \& maternal health utilisation in Ghana. Soc Sci Med. 2006;62:2930e2944.

12. Antai $D$, Ghilagaber G, Wedren S, Macassa G, Moradi T. Inequities in under five mortality in Nigeria: differentials by religious affiliation of the mother. $J$ Relig Health. 2009;48(3):290e304.

13. Zimbabwe National Statistics Agency and ICF International. Zimbabwe demographic and health survey 2015: final report. Rockvill: Zimbabwe National Statistics Agency (ZIMSTAT) and ICF International; 2016.

14. Chitando E. Living with Hope: African churches and HIV/AIDS 1. Geneva: WCC Publications; 2007.

15. Chitando E, Gunda MR, Kuegler J. Multiplying in the Spirit: Introduction. In: Chitando E, Gunda MR, Kuegler J, editors. Multiplying in the Spirit: African Initiated Churches in Zimbabwe. edn. Bamberg: University of Bamberg Press; 2014.

16. Chari T. "Suspect Spirituality"? Media Representation of African Independent Churches in Zimbabwe. In: Chitando E, Gunda MR, Kügler J, editors. Multiplying in the Spirit: African Initiated Churches in Zimbabwe. edn: University of Bamberg Press; 2014. p. 109-27:e0160170. https://doi.org/10.13 71/journal.pone.0160170.

17. Central Statistical Office [Zimbabwe] and Macro International Inc. Zimbabwe Demographic and Health Survey, 1994. Calverton, Maryland: Central Statistical Office and Macro International Inc; 1995.

18. Zimbabwe National Statistics Agency (Zimstat). Zimbabwe Multiple Indicator Monitoring Survey (MIMS). Final Report. Harare; 2009.

19. Ranger T. Taking on the missionary's task: African spirituality and the mission churches of Manicaland in the 1930s. J Relig Afr. 1999;29(2):175-205.

20. Gregson S, Zhuwau T, Andersen RM, Chandiwana SK. Apostles and Zionists: the influence of religion on demographic change in rural Zimbabwe. Popul Stud. 1999;53:179e193.

21. Hove I, Siziya S, Katito C, Tshimanga M. Prevalence and associated factors for non-utilisation of postnatal care services: population-based in Kuwadzanaperi-urban area, Zvimba district of Mashonaland West Province, Zimbabwe. Afr J Reprod Health. 1999:3(2):25e32.

22. Manzou R, Schumacher C, Gregson S. Temporal dynamics of religion as a determinant of HIV infection in East Zimbabwe: a serial cross-sectional analysis. PLoS One. 2014;9(1):e86060.

23. Hallfors DD, Cho H, Iritani BJ, Mapfumo J, Mpofu E, Luseno WK, January J. Preventing HIV by providing support for orphan girls to stay in school: does religion matter? Ethn Health. 2013;18(1):53-65.

24. Ministry of Health and Child Care (MOHCC), Zimbabwe. Zimbabwe Population-Based HIV Impact Assessment (ZIMPHIA) 2015-16: First Report. Harare: MOHCC; 2017.

25. Central Statistical Office/Zimbabwe, Macro International. Zimbabwe Demographic and Health Survey 2005-06. Calverton, Maryland, USA: Central Statistical Office/Zimbabwe and Macro International; 2007.

26. Pearson S, Makadzange P. Help-seeking behaviour for sexual-health concerns: a qualitative study of men in Zimbabwe. Cult Health Sex. 2008; 10(14):361e376.

27. Hallfors DD, Iritani BJ, Zhang L, Hartman S, Luseno WK, Mpofu E, Rusakaniko S. 'I thought if I marry the prophet I would not die': the significance of religious affiliation on marriage, HIV testing, and reproductive health practices among young married women in Zimbabwe. SAHARA J. 2016;13(1):178-87.

\section{Publisher's Note}

Springer Nature remains neutral with regard to jurisdictional claims in published maps and institutional affiliations.

Ready to submit your research? Choose BMC and benefit from:

- fast, convenient online submission

- thorough peer review by experienced researchers in your field

- rapid publication on acceptance

- support for research data, including large and complex data types

- gold Open Access which fosters wider collaboration and increased citations

- maximum visibility for your research: over $100 \mathrm{M}$ website views per year

At BMC, research is always in progress.

Learn more biomedcentral.com/submissions 